\title{
TQM IMPLEMENTATION EFFECT ON BAHRAIN INDUSTRIAL PERFORMANCE
}

\author{
B. Al Mannai and S. Suliman \\ Department of Mechanical Engineering \\ University of Bahrain, Isa Town, Kingdom of Bahrain \\ Y. Al Alawai \\ Bahrain Institute for Political Development, \\ Um Al Hassam, Kingdom of Bahrain
}

\begin{abstract}
Research studies on the implementation of Total Quality Management (TQM) demonstrated that the program can improve organizations competitive abilities and provide strategic quality advances. However, limited empirical studies and research have been conducted in Bahrain evaluating the effectiveness of TQM implementation on the industrial organizations performance. Accordingly, this paper aims to measure the degree of TQM implementation in the industrial organizations in Bahrain and its effect on their performance. The paper presents the measurement indicators used to assess the degree of TQM implementation in Bahrain industry, and the main performance indicators affected by it. The adopted research methodology is a survey based on selfcompletion questionnaires. The study led to the identification of the operational and strategic measurement indicators and success factors that assist in successful TQM implementation and performance improvement. The research analysis confirmed a significant positive relationship between the examined performance indicators in Bahrain industry and TQM implementation, and highlighted the key performance improvements.
\end{abstract}

Key words: Industrial Organizations, Performance Indicators, Success Factors, TQM Implementation.

Cite this Article: B. Al Mannai, S. Suliman and Y. Al Alawai, TQM Implementation Effect on Bahrain Industrial Performance, International Journal of Industrial Engineering Research and Development, 8(1), 2017, pp. 20-26. https://iaeme.com/Home/issue/IJIERD?Volume=8\&Issue=1

\section{INTRODUCTION}

Over the last two decades, quality has become one of the most important factors in ensuring business survival and growth. According to Munizu [1], continuous Quality improvement is considered a competitive advantage and a strategic tool around the world to meet the challenges of global competition today. Many forms of quality techniques and practices in the literature are discussed and employed to achieve continuous quality improvement, and Total Quality Management (TQM) has proved to be among the most effective quality techniques that have been applied [2]. In addition, vast empirical studies have shown that TQM implementation can significantly affect the results and business impact [1]-[4]. 
TQM is an integrative management philosophy based on three fundamental aspects: commitment to never ending improvement in quality to the customer, involvement of all the team members to achieve a common goal, and continuous improvement to eliminate any error or defect [7].

According to Paksoy et al. [4], TQM is defined as an action plan to produce and deliver commodities, which are consistent with customers' needs or requirements by better, cheaper, faster, safer, easier processing than competitors with the participation of all employees under top management leadership. Further, they state that TQM is based on two core concepts: hard and soft concepts. The hard concepts are statistical methods such as Pareto analysis, control charts, Ishakawa diagrams, system tools and performance evaluation. Whereas, training, employee recognition and teamwork are regarded as soft aspects.

The outcomes of adopting this philosophy and implementing TQM have shown positive relationship between TQM implementation and organization performance. Moreover, according to Reed et al. [5], there is a growing body of literature and research supporting a direct relationship between the adoption of TQM and improved firm performance. In addition, research studies investigated the critical success factors of TQM on industry performance, small and medium size enterprises (SMEs), to help organizations implement TQM principles and practices more effectively.

However, a literature review of the previous studies on TQM Key practices and successful implementation factors provided different sets of practices and success factors. The common TQM elements and success factors in the literature includes: top management commitment and recognition, customer focus, continuous improvement, measurement and feedback, teamwork and involvement, training and development, and communication in company [4], [8], [9]. On the other hand, Talib [7] identified two extra success factors: benchmarking and supplier management. Moreover, Brah et al. [10] stated three additional success factors: employee empowerment, service design, and cleanliness; and Powell [3] added another success factor: flexible manufacturing.

Moreover, according to Talib [7], this led to inconsistencies that made it difficult to reach a conclusion on the success factors of TQM implementation. He further pointed out that the set of success factors chosen depends upon the nature and characteristics of the organization which is responsible for successful implementation of TQM program and improved performance.

On the other hand Sugimori et al. [6], discussed the studies conducted in Australian and New Zealand manufacturing organizations that examined the effect of TQM practices on operational performance of a large number of manufacturing companies in Australia and New Zealand, and pointed out that the relationship between TQM practice and organizational performance is significant, but not all of the categories of TQM practice were particularly strong predictors of performance. In addition, Munizu [1] states that most researchers found a positive relationship between TQM practices and performance.

Bahrain industry composes of various sectors ranging from large to small industrial organizations, and few organizations adopt TQM program to sustain local and global competitive advantage. However, in Bahrain insufficient research is conducted to investigate the degree of TQM implementation and its effectiveness on the organizations performance.

Consequently, in an effort to promote and encourage TQM implementation, it is crucial for the industrial and manufacturing organizations in Bahrain to comprehend the performance improvements gained by the local organizations from TQM implementation, and the success factors that lead to successful implementation in Bahrain.

Based on the above, and the fact that nothing has been written on how effective TQM implementation on Bahrain industries performance in literature, the aim of this study is to assess the degree of TQM implementation on Bahrain industries and reveal its effectiveness on Bahrain industries performance. 


\section{METHODOLOGY}

To accomplish the aim and objects of this study, a survey based on a self-completion questionnaire was adopted. The self-completion questionnaire included both qualitative and quantitative data.

To address the degree of TQM implementation, 2 sets of questionnaires were developed, based on perceptual and objective evaluation. The first set of questionnaire (strategic) was deployed to extract the top management practice and point of view, to determine the effect of the quality programs on the organization performance, as well as revealing correlation that supports improved performance. The second set of questionnaire (operational) was deployed to extract the operational employees and workforce practices and point of view, to determine the degree of TQM program application.

On the other hand, to address the effect of TQM implementation on the organization performance, a set of questionnaire was deployed to extract the top management point of view.

The large and medium size industrial and manufacturing organizations in Bahrain formed the population of the study. Bahrain Ministry of Industry and Commerce classification (large and medium size organizations) was used to enable better sample selection representation. Accordingly, the industrial and manufacturing organizations selected for this study were limited to organizations that have a workforce not less than 50 employees, and an annual turnover that exceeded 2.5 million US Dollars.

A total of 39 organizations resulted from the database that met the selection criteria, and 15 positive responses were received, representing $38.5 \%$ response rate. The majority of respondents represented the large size industrial and manufacturing organizations, 10 organizations, and the remaining 5 organizations represented the medium size organizations.

The study findings were computed on the bases of averaging the summation responses, at the operational and strategic level. Furthermore, there was no intention of studying the correlation between the large and medium size organizations results, and thus the results breakdown presented in this study was for explanatory purpose.

\section{RESULTS AND DISCUSSION}

Based on the TQM implementation success factors and measurement indicators extensive literature survey, the operational success factors, strategic success factors, measurement indicators, and performance improvement indicators necessary to assess the degree of TQM implementation and effect on Bahrain industrial performance were developed.

The assessment of the degree of TQM implementation, at the operational level, was based on 29 measurement indicators grouped into 9 success factors. The 9 operational level success factors are: Quality Certifications, Quality Procedures, Focused Improvements, Information and Feedback, Employee Training, Employee Participation, Employee Satisfaction, Customer Satisfaction, and Supplier Quality.

Whereas, the assessment of the degree of TQM implementation, at the strategic level, was based on fifteen measurement indicators grouped into 6 success factors. The 6 strategic level success factors are: Leadership, Focused Improvements, Information and Feedback, Employee Participation, Employee Satisfaction, and Supplier Quality. Table I summaries the degree of success factors implementation in both levels (operational and strategic). Accordingly, the 4 strategic and operational common success factors were grouped.

As can be seen from Table I, all the organizations scored (100\%) in leadership success factor implementation. All of the respondents strongly agreed that their top management supported the long-term quality improvement programs, plant management were involved in these improvements, and their top management had periodical quality review meetings.

In addition, it was found that all the organizations scored (100\%) in quality procedures success factor implementation. All of the respondents strongly agreed that their organization had quality procedures 
available. Furthermore, the analysis revealed that $(67 \%)$ of the respondent use both offline and online quality inspection in their organization.

Moreover, all the organizations scored (100\%) in focused improvement success factor implementation. All of the respondents strongly agreed that their organization understand the nature of their quality problems and have well established quality information measures.

Table 1 Degree of TQM success factors implementation

\begin{tabular}{|l|c|c|c|}
\hline \multicolumn{1}{|c|}{ Success Factor } & $\begin{array}{c}\text { Implementation } \\
\text { All (\%) }\end{array}$ & $\begin{array}{c}\text { Implementation } \\
\text { Large (\%) }\end{array}$ & $\begin{array}{c}\text { Implementation } \\
\text { Medium (\%) }\end{array}$ \\
\hline Leadership & 100 & 100 & 100 \\
\hline Quality Procedures & 100 & 100 & 100 \\
\hline Focused Improvement & 100 & 100 & 100 \\
\hline Supplier Quality & 91 & 89 & 92 \\
\hline Customer Satisfaction & 90 & 91 & 89 \\
\hline Employee Participation & 89 & 95 & 83 \\
\hline Information And Feedback & 89 & 92 & 85 \\
\hline Employee Satisfaction & 88 & 93 & 82 \\
\hline Employee Training & 88 & 81 & 94 \\
\hline Quality Certification & 86 & 89 & 83 \\
\hline
\end{tabular}

Further, it was found that the most implemented quality improvement tool was Plan Do Check Act (PDCA) cycle (80\%), when compared against Statistical Process Control (SPC), Six Sigma, Quality Circles implementation, Failure Mode and Effect Analysis (FMEA), and Quality Function Deployment (QFD); as shown in Fig. 1.

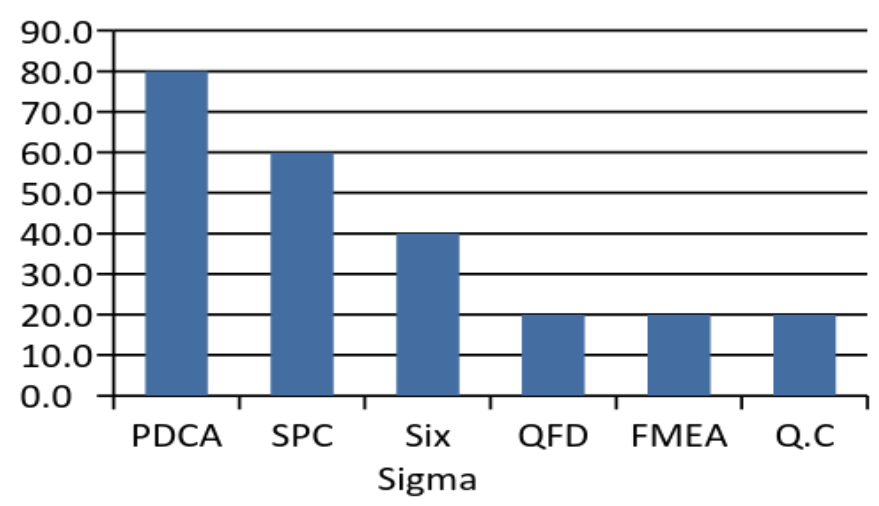

Figure 1 Quality improvement tools implementation

However, the quality certification success factor implementation was the least (86\%). In addition, the training success factor unexpectedly was found to be lower in large size organizations (81\%) when compared against medium size organizations (94\%). Generally, it would have been expected that large organizations would score higher than medium size organizations and not vice versa, due to the fact that large organizations usually have dedicated budgets for employee training and development.

The assessment of TQM implementation effect on organization performance was based on 31 performance improvement indicators. The indicators were grouped into 6 performance dimensions, namely: sales, workforce, quality, delivery, process, cost performance. The strategic level assessment was based on the strategic. Table II summaries the TQM implementation effect on organization performance. 
TQM Implementation Effect on Bahrain Industrial Performance

Table 2 TQM implementation effect on organization performance

\begin{tabular}{|l|c|c|c|}
\hline \multicolumn{1}{|c|}{ Performance Dimension } & $\begin{array}{c}\text { Implementation } \\
\text { Effect All (\%) }\end{array}$ & $\begin{array}{c}\text { Implementation } \\
\text { Effect Large (\%) }\end{array}$ & $\begin{array}{c}\text { Implementation } \\
\text { Effect Medium (\%) }\end{array}$ \\
\hline Workforce Performance & 87 & 90 & 80 \\
\hline Sales Performance & 86 & 83 & 92 \\
\hline Quality Performance & 84 & 87 & 80 \\
\hline Delivery Performance & 67 & 75 & 50 \\
\hline Process Performance & 67 & 83 & 33 \\
\hline Cost Performance & 61 & 78 & 28 \\
\hline
\end{tabular}

As can be seen from Table II, the highest positive effect of TQM implementation on organization performance was found to be on the workforce (87\%). All of the organization respondents indicated that TQM implementation had significant impact on workforce professionalism improvement (within the workforce performance dimension).

In addition, there was clear impact on sales performance (86\%). The majority of organization respondents indicated that TQM implementation had significant impact on the following performance improvement indicators (within the sales performance dimension): organization image improvement, and new customer base establishment. The quality performance dimension achieved similar overall results $(84 \%)$, as the workforce dimension. All of the organization respondents indicated that TQM implementation had significant impact on the following performance improvement indicators (within the quality performance dimension): product performance and reliability improvement, employees' quality awareness and appreciation improvement, and internal customer satisfaction rate increase.

Surprisingly, the lowest positive effect of TQM implementation on organization performance was found to be on cost $(61 \%)$. The majority of organization respondents indicated that TQM implementation had significant impact on the following performance improvement indicators (within the cost performance dimension): overhead cost, and material cost reduction.

The next part of the analysis involves presenting the overall TQM implementation results versus the overall implementation effect on Bahrain industrial performance, which is the focus of this survey. The degree of TQM implementation and effect on performance for all, large and medium size organizations, is summarized in Fig. 2.

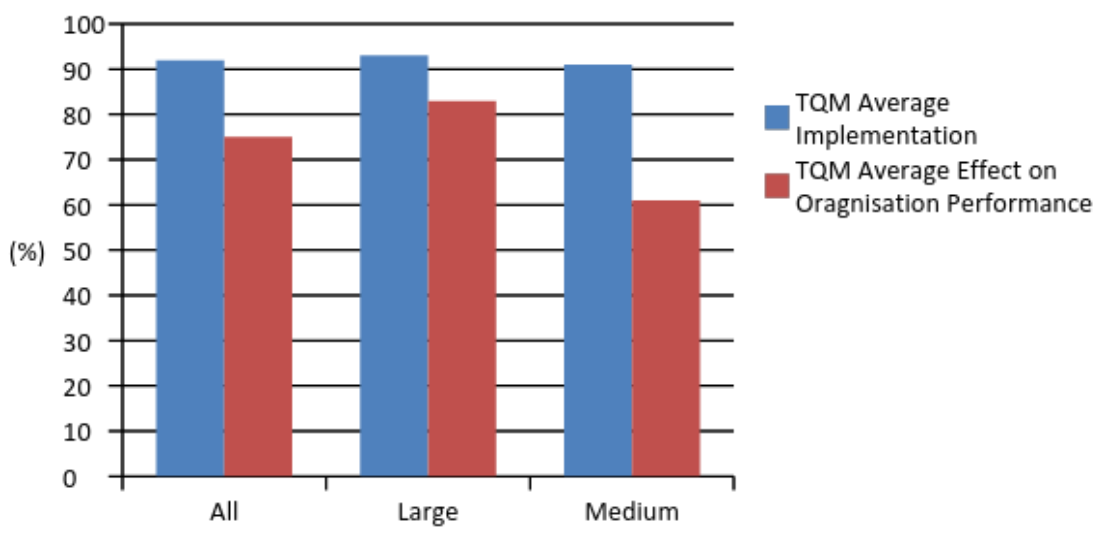

Figure 2 Degree of TQM implementation and effect on organization performance

Based on the overall results analyses, the TQM implementation evaluation clearly demonstrate that the industries in Bahrain have well established leadership, quality inspection procedures, and focused improvement programs.

The degree of TQM implementation over the entire industrial and manufacturing organizations surveyed in Bahrain was found to be $(92 \%)$. The results revealed that the degree of TQM implementation 
in the large organizations surveyed was higher (93\%) in comparison with the medium organizations $(91 \%)$. The slight differences between the large and medium size organizations results indicate that equivalent efforts have been exerted by the two sectors towards the implementation of TQM. Therefore, it can be concluded that TQM implementation is adequately established in the investigated organizations, and this is an indication of awareness of the importance of TQM program to realize a competitive advantage over their national, regional, and international competitors.

Furthermore, Fig. 2 shows that the TQM implementation (92\%) resulted in an overall $(75 \%)$ improvement in organization performance. The efforts exerted towards TQM implementation in the large organizations surveyed (93\%) produced great overall performance improvements $(83 \%)$.

Unexpectedly, however, it was found that the TQM implementation efforts exerted by the medium size organizations surveyed (91\%) achieved extremely lower overall performance improvements (61\%), which was due to the insignificant impact on cost and process performance improvement. The construct validity of the instrument is computed by calculating the convergent validity and divergent validity. Visual PLS does this by calculating average variance extracted and correlation of latent variables.

\section{CONCLUSION}

The aim of this study was to assess the degree of TQM implementation on Bahrain industries and reveal its effectiveness on Bahrain industries performance. From the operational and strategic TQM success factors assessment, it was found that the degree of TQM implementation over the industrial and manufacturing organizations surveyed in Bahrain was (92\%). These results indicate that TQM implementation is adequately established in the investigated organizations, and reflected top management awareness of the importance of TQM program implementation.

Furthermore, this study revealed that TQM implementation had positive and significant effect toward organizational performance improvement. Overall TQM implementation resulted in (75\%) improvement in the organizational performance. The investigation of the relationship between TQM implementation and the performance indicators revealed an overall significant improvement in workforce performance dimension, sales performance dimension, and quality performance dimension with overall average of $87 \%$, $86 \%$, and $84 \%$ respectively.

In addition the results revealed that the most implemented quality improvement tool was Plan Do Check Act (PDCA) cycle (80\%). Therefore, as a recommendation for further enhancement of performance, attention should be directed towards SPC and QFD initiatives.

Although this study successfully achieved the set objectives, there are opportunities for further in-depth investigation to explore how industrial organizations can measure and link the critical success factor to their organizational performance improvement.

\section{AKNOWLEDGEMENT}

This material was based on research supported by the Deanship of Scientific Research [grant No. 2010/21], University of Bahrain.

\section{REFERENCES}

[1] M. Munizu, The impact of total quality Management practices towards competitive advantage and organizational performance: case of fishery industry in South Sulawesi province of Indonesia, Pak. J. Commer. Soc. Sci., 7(1), pp.184-197, 2013.

[2] A. Korankye, Total quality management (TQM): a source of competitive advantage. A comparative study of manufacturing and service firs in Ghana, Int. J. of Asian Soc. Sci., 3(6), pp. 1293-1305, 2013.

[3] T. Powell, Total quality management as competitive advantage: a review and empirical study, Strategic Mgmt. J., 16(1), pp. 15-37, Jan. 1995. 
[4] H. Paksoy, P. Paksoy, M. Marangoz, and M. Özçalici, TQM perception in Turkey: a comparison of industries, African J. of Business Mgmt., 5(8), pp. 3188-3198, Apr. 2011.

[5] R. Reed, D. Lemak, and N. Mero, Total quality management and sustainable competitive advantage, $J$. of Quality Mgmt., Volume 5, pp. 5-26, 2000.

[6] Y. Sugimori, K. Kusunoki, F. Cho, and S. Uchikawa, Toyota production system and kanban system: materialization of Just-in-Time and respect for human systems, Int. J. of Production Res, 15(6), pp. 553564, 1977.

[7] F. Talib, An Overview of Total Quality Management: Understanding The Fundamentals In Service Organization. Int. J. of Adv. Quality Mgmt, 1(1), pp. 1-20, 2013

[8] D. Mittal, V. Singla, and A. Goyal, Comparison of TQM success factors in northern India in manufacturing and service industries: a survey. Int. J. of Eng. Sci. and Tech, 3(2), pp. 1368-1377, 2011.

[9] Q. Eng, and S. Yusof, A survey of TQM practices in the Malaysian electrical and electronic industry, $J$. of Total Quality Mgmt., 14 (1), pp. 63-77, 2003.

[10] S. Brah, J. Wong, and M. Rao, TQM and Business Performance in the Service Sector: A Singapore Study," Int. J. of Operation and Production Mgmt, 20(11), pp. 1293-1312, 2000.

[11] P. Rupha rani, Critical Success Factors of TQM: A Study. International Journal of Management, 4(1), 2013, pp. 266-275.

[12] Smitha Nair and A.Ramachandran, Gap Analysis for Implementing TQM in Seafood Exporting Firms. International Journal of Management, 4(4), 2013, pp. 49-59.

[13] Neha Kalra and Anoop Pant, TQM-A Management Philosophy in Indian Automobile Industry (NCR). International Journal of Management, 4(6), 2013, pp. 12-20. 